\title{
NOVA ABORDAGEM NO TRATAMENTO DA ESQUIZOFRENIA
}

\author{
WALTER SPELTRI *
}

A esquizofrenia, pela sua freqüência, gravidade e importância social, constitui o principal problema da Psiquiatria. Não obstante seja uma das enfermidades mais exaustivamente estudadas sob todos os aspéctios, persistem as discussōes quanto à sua etiologia, tendo ocorrido, ultimamente, nítido desvio das investigações para o sistema neurovegetativo, à procura da origem do processo.

Neste sentido chamam a atenção recentes trabalhos de Nelson Pires ${ }^{6}$. ', a propósito de bons resultados terapêuticos obtidos em diversas enfermidades psiccssomáticas, principalmente no que se refere ao sintoma dôr, pois, atuando na periferia, o referido autor conseguiu fazer desaparecer tôda sintomatologia. Bas€ados nêsses trabalhos, passamos a admitir a hipótese de ser a esquizofremia uma enfermidade psicossomática, considerando, como o faz Nelson Pires, que "o psíquico é um circuito intercalado no trajeto de um circuito muito mais longo de aferências e eferências".

A partir de abril de 1963, utilizámos, no tratamento da esquizofrenia, substância considerada farmacológicamente como simpaticoplégica e conseguimos resultados significativos. Tais resultados mostram que é possivel interferir na patogenia da esquizofrenia agindo-se na periferia neural, o que permite fazer pequena correção à célebre frase atribuída a Griesinger e dizer que as doenças mentais não são, necessária e fundamentalmente, doenças cerebrais.

Utilisamos a Guanetidina, substância identificada químicamente como sulfato de 2-(octaidro-l-azocinil)-etilguanidina, sintetizada por Maxivell, Mull e Plummer ${ }^{4}$. Não se conhece com precisão seu mecanismo de ação, embora seja considerada, do ponto de vista farmacodinâmico, como simpaticoplégica, ou seja, substância que inibe ou diminui a liberaçāo de catecolaminas (adrenalina e noradrenalina) pelas fibras nervosas simpáticas pós-ganglionares ${ }^{1 . "}$. Maxwell e col. ${ }^{4}$ admitem que o seu mecanismo de ação esteja ligado à inibição e/ou à distribuição das substâncias transmissôras das terminações nervosas simpáticas ao nivel do efetor. A Guanetidina distingue-se, pois, dos ganglioplégicos porque não atua ao nível das estruturas ganglionares. Difere, tambẻm, dos simpaticoliticos que não inibem a liberação das catecola-

Trabalho do Hospital de Juqueri, apresentado em reunião conjunta do Centro de Estudos "Franco da Rocha" e do Departamento de Psiquiatria da Associação Paulista de Medicina, em 14 de outubro de 1965. * Psiquiatra, chefe da Seção Masculina. 
minas pelas fibras pós-ganglionares simpáticas, porém impedem a reação do orgão efetor às referidas substâncias. Finalmente, não se assemelha aos adrenolíticos, cujo mecanismo de ação fundamental é a lise das catecolaminas. Maxwell e col.5 demonstraram que a guanetidina atua no espaço compreendido entre os gânglios periféricos e os receptores que são influenciados pelos adrenolíticos. A ausência de efeito central foi comprovada em ratos nos quais, após administração da referida substância, ocorreu diminuição da taxa de catecolâminas no coração, baço e paredes arteriais, sem que houvesse diminuição no cérebro. Importante é o fato de a Guanetidina não só ter efeito pronunciado na hipertensão neurogênica experimental mas, também, inibir a elevação tensional de curta duração, conseqüente aos estímulos exógenos. Foi comprcvado experimentalmente que, após a administração de $15 \mathrm{mg} / \mathrm{Kg}$, os animais não reagem aos estímulos exógenos, senão ao cabo de 9 dias.

\section{MATERIAL E METODOS}

Tratámos 11 casos de esquizofrenia: dois de forma catatônica, um de forma simples, um de forma hebefrênica, 6 de forma paranóide e um de forma parafrênica. Consideramos como agudos os casos com menos de um ano e, como crônicos, os de mais de um ano de evolução. De acôrdo com êsse critério, os três primeiros (casos $1,2,3)$ eram agudos e os 6 seguintes (casos 4, 5, 6, 7, 8 e 9) crônicos; nos dois últimos (casos 10 e 11) não obtivemos informações precisas quanto ao tempo de evolução. Na captação dos sintomas psicopatológicos utilizámos o método analítico-descritivo, sendo o diagnóstico estabelecido, tanto quanto possivel, em sentido pluridimensional. Fundamentalmente, seguimos a orientação diagnóstica nos moldes de K. Schneider 8 .

Utilizábos o medicamento * sob a forma de comprimidos, dosados de 10 e $25 \mathrm{mg}$, em tomada única, pela manhã. A pressão arterial, o pulso e a temperatura foram verificados duas vêzes ao dia, pela manhã e a tarde. Iniciámos o tratamento com 10 ou $12,5 \mathrm{mg}$ díários e aumentávamos progressivamente, na mesma dosagem, cada 5-10 dias, quando percebiamos que a dóse então usada já não produzia efeito.

Verificámos que a sintomatologia melhorava à medida que aumentávamos a dose diária, até atingírmos valôres compreendidos entre 60 e $75 \mathrm{mg}$, valôres que consideramos como dose máxima útil. Doses superiores não se mostraram mais úteis, podendo, inclusive, diminuir a intensidade da melhora obtida. Assim, em 5 casos, ao atingímos doses díálas de 100 e $125 \mathrm{mg}$, observámos o recrudescimento da sintomatologia, novamente melhorada com a ulterior redução da dosagem. A comprovaçāo do efeito quando se alteram as doses, para mais ou menos, demanda certo periodo de tempo, variável entre 5 e 10 dias. Apesar de termos atingido, em alguns casos, doses diárias de $125 \mathrm{mg}$, nāo verificámos efeitos colaterais que obrigassem à interrupção do tratamento.

$O$ inicio da melhora se deu entre o 5.9 e o 20.9 dia de tratamento, em média no 10.9 dia. O tempo de duração dos tratamentos variou entre 47 e 184 dias, 90 em média. A remissão total da sintomatologia ocorreu, porém, muito antes, entre os 22 e os 72 dias de tratamento, em média no $40 .^{\circ}$ dia. A suspensão precoce do medicamento faz reaparecer os sintomas após 5 a 10 dias. A manutenção da dose máxima útil por um tempo médio de 30 dias, após a remissão total, mantém a cura clínica. Em dois casos nos quais interrompemos o tratamento logo após a cura clinica, a sintomatologia reapareceu integralmente. Reiniciado o tratamento,

* Agradecemos a Produtos Químicos Ciba S.A. o fornecimento da Guanetidina. 
conseguimos nova rémissão total, embora mais demorada e exigindo doses maiores, como se tivesse ocorrido resistência à droga após a primeira administração. Não prescrevemos o medicamento em doses de manutenção para nenhum dos 11 casos.

\section{RESULTADOS}

Os 11 pacientes esquizofrênicos responderam significativamente ao tratamer.to. Dos 11, dois não concluiram o tratamento: em um dêles não soubemos valorizar devidamente a remissão que vinha ocorrendo e interrompemos a administração do medicamento no 39.9 dia de tratamento; o outro fugiu do hospital depois de ter completado o mesmo tempo de tratamento. Ambos apresentavam indiscutíveis melhoras. Dos 9 casos restantes, 6 remitiram totalmente e três parcialmente. Quanto a um dèstes três últimos casos, embora houvesse evidente melhora, não temos condições para afirmar se houve remissão completa devido à carência de informações quanto à personalidade pré-mórbida; os outros dois eram os únicos oligofrênicos do grupo.

1) Resultados de acôrdo com o tempo de evolução - Os três casos agudos remitiram totalmente $(100 \%)$. Dos 6 casos crônicos, dois $(33,33 \%)$ não terminaram o tratamento, mas apresentaram indiscutivel remissão parcial durante o tempo em que permaneceram sob a ação da guanetidina; dos 4 restantes, três (75\%) remitiram totalmente e um $(25 \%)$ remitiu parcialmente (é o oligofrênico do grupo). Nos dois casos cujo tempo de evolução era duvidoso houve remissão parcial; um era oligofrênico; do outro não temos informes quanto à personalidade pré-mórbida.

2) Efeitos observados - O medicamento produziu efeitos nas três esferas psiquicas (intelectual, afetiva e ativa): desapareceram as alucinações; normalizaram-se a atençāo, a excitação e agressividade; cedeu a produção delirante com seu núcleo de "humor delirante"; cedeu a interceptação do pensamento; cedeu a desagregaçāo e a incoerência; foram facilitados o contato e a penetração psicológica, tendo os pacientes readquirido o "tom afetivo" e a acessibilidade social básicos.

3) Tempo de evolução e tratamentos anteriores à guanetidina - Nos très casos agudos, o tempo de evolução foi de 3,6 e 9 mêses. Nos três casos tratava-se da primeira internação. Um paciente ainda não tinha sido submetido a tratamento algum; outro já tinha sido submetido a eletrochoques e insulinoterapia; no terceiro já tinham sido feitos eletrochoques, impregnação e insulina. Êstes dois últimos enfermos nāo apresentaram melhoras com os tratamentos instituídos.

Nos 6 casos crônicos o tempo de evolução variou entre 16 mêses e 10 anos, com média de 3,8 anos. Um dêsses doentes (caso 4) esteve internado 4 vêzes em 7 anos, em diferentes hospitais: na primeira internação foi tratado com insulina e eletrochoques e, nas restantes, com impregnação pela clorpromazina. Teve alta, após cada uma dessas internações sem apresentar melhoras nítidas, apenas "um pouco mais calmo". Internado no Hospital de Juquerí, foi submetido a diversos tratamentos (impregnação pela trifluorpromazina e flufenazina, 30 comas insulînicos e 30 comas insulínicos associados ao eletrochoque) num período de dois anos, sem apresentar qualquer melhora. Em 29/4/1963 iniciamos a administraçāo da guanetidina e a sintomatologia remitiu totalmente. Este enfermo, o primeiro em que utilizamos êste medicamento, permaneceu internado durante todo o tempo de tratamento (135 dias). O inicio da melhora deu-se antes de completar 20 dias de tratamento; a remissão total foi observada na 9.a semana e o paciente começou a estabelecer "insight" no terceiro mês. Concedemos alta clínicamente curado. Depois de 8 meses, durante os quais permaneceu clínicamente curado, ocorreu recidiva. Reinternado, o paciente foi submetido novamente à guanetidina e obtivemos, apenas, remissão parcial da sintomatologia. Em seguida, submetido a impregnação com um derivado butirofenônico, ocorreu remissão total. Teve alta, em licença experimental, em 13/4/1965. 
Outro enfermo (caso 5) também esteve internado por três vêzes. Nas duas primeiras internaçōes foi submetido a eletrochoques e teve alta "bom", retornando ao trabalho. Na terceira internação submeteram-no a 30 comas insulínicos associados a eletrochoques e mais um coquetel litico (Amplictil, Fenergan e Gardenal), tendo tido alta, embora apresentando "acentuada carência de iniciativa". Internado no Hospital de Juqueri, foi submetido a tratamento com eletrochoques e, ulteriormente, a 30 comas insulínicos, sem resultado. Prescrevemos mais 4 eletrochoques, havendo remissão parcial da sintomatologia, o que possibilitou ao paciente passar 6 meses com seus familiares e o retorno ao trabalho. Reinternado, pouco antes de completar 6 meses de licença, com agravamento da sintomatologia, submetemo-lo à guanetidina e conseguimos a remissão total.

O caso 6 estava internado no Hospital de Juqueri há 20 meses, sendo essa sua primeira internação. Submetemo-lo à impregnação e a 30 comas insulinicos sem resultado. Iniciamos o tratamento pela guanetidina em 26/6/1963. No 20.9 dia de tratamento iniciou-se a remissão e, aos 39 dias, era já acentuada, mas cometemos um êrro na avaliação dos resultados que vinhamos obtendo e interrompemos o tratamento, com o que o enfermo piorou acentuadamente. Sob a ação da guanetidina o paciente tornou-se muito menos agressivo, melhorou o contato e a penetração psicológica, houve distanciamento do delírio e as alucinações desapareciam quando estava no quarto forte. Nosso êrro consistiu no fato de não sabermos que o "distanciamento do delírio em relação ao EU" era sinal de melhora e que o desaparecimento das alucinaçōes no quarto-forte tivesse algum valor.

o caso 7 esteve internado por duas vêzes em sanatórios particulares, mas ignoramos os tratamentos a que foi submetido. Sabemos apenas que teve alta "um pouco melhor". Internado no Hospital de Juqueri, submeteram-no à 30 comas insulinicos e impregnação pela trifluorpromazina. Considerado em remissão parcial, concederam-lhe "licença experimental" de 90 dias. Retornando da licença com recidiva, ficou sob nossos cuidados e foi submetido à guanetidina, com o que conseguimos remissāo total da sintomatologia.

O caso 8 esteve internado pela primeira vêz no Hospital de Juqueri em 1961, tendo sido submetido a 30 comas insulinicos e impregnação pelo Trilafon. Teve alta em "remissão social" em março de 1962. Reinternado um ano depois, submeteram-no a três eletrochoques, cujo resultado não foi possivel apreciar por ter fugido do hospital. Retornou menos de um mès depois. Iniciamos o tratamento pela guanetidina e apresentava indiscutivel remissão parcial quando, ao completar o 39.9 dia de tratamento, fugiu novamente e não retornou até esta data.

o caso 9, um dos oligofrênicos, foi internado em outubro de 1962 . Era a primeira vêz que apresentava distúrbios mentais. Esteve em tratamento, por longo tempo, de uma intercorrência clinica ("sindrome nefrótico acompanhado de insuficiência hepática"). Considerado curado da intercorrēncia, permaneciam os sintomas psicopatológicos. Fizemos 30 comas insulínicos sem resultado. Submetemo-lo a quanetidina e conseguimos remissão parcial da sintomatologia.

Nos dois casos, cujo tempo de evolução era duvidoso, tinham sido feitos, também, outros tratamentos sem resultado. No caso 10 , nem os parentes mais próximos sabiam o que tinha se passado com o enfermo, que esteve "desaparecido" durante 8 anos e, após êsse tempo, retornou à residência com sintomas de doença mental. Internado no Hospital de Juquerí 15 dias depois, foi submetido a 5 eletrochoques e 30 comas insulínicos sem sucesso. Com o tratamento pela guanetidina obtivemos remissão que não podemos garantir ter sido total por falta de informes quanto à personalidade pré-mórbida, mas a remissão obtida era indiscutivel.

No caso 11 não conseguimos precisar a data do início da enfermidade por falta de informes, havendo apenas indícios para supor que a doença se instalou em março de 1963, ocasião em que foi internado no Hospital de Juqueri. Administraram-lhe, durante 55 dias, um derivado butirofenônico, na dose de $3 \mathrm{mg}$ diários, sem resultado. Tratado com a guanetidina, conseguimos a remissão parcial da sintomatologia. Este paciente é o outro dos dois oligofrênicos do grupo.

4) Associação de outros medicamentos com a guanetidina - Nos três casos agudos não empregamos nenhum outro medicamento durante o tratamento com a 
guanetidina. Dos 6 casos crônicos, fizemos tratamentos associados em três. No caso 4, o primeiro que submetemos ao tratamento pela guanetidina, ficamos recєiosos de que, ao interrompermos a medicação, o paciente retornasse ao seu estado anterior. O enfermo achava-se pràticamente curado e, "como tentativa de consolidar a cura", submemo-lo à impregnação pela trifluorpromazina, o mesmo medicamento e, inclusive, com a mesma técnica que já o tínhamos empregado anteriormente sem resultado. O importante, contudo, é que, após a impregnação, não notamos modificação no ritmo da melhora que o paciente vinha obtendo. No caso 5 , aplicamos 5 eletrochoques e não verificamos nenhuma modificação nos "restos de enfermidade" que a guanetidina não conseguira eliminar. Só depois de colhermos os dados anamnésticos que faltavam (fornecidos por dois irmãos, a espôsa e a filha, separadamente), convencemo-nos tratar-se de um traço característico de sua personalidade pré-mórbida. Mais de três mêses após a interrupção do tratamento houve nôvo surto que remitiu de nôvo, totalmente, após submete-lo à guanetidina e sem que fizessemos eletrochoques. No caso 9 (esquizofrenia em oligofrênico) fizemos 30 comas insulinicos associados à guanetidina e não observamos modificação nos resultados que já tinhamos obtido com a guanetidina antes de submeter o paciente ao método de Sakel. Nos casos em que o tempo de evolucĩo era duvidoso também fizemos tratamento associado. No caso 10 aplicamos eletrochoques e, no caso 11, fizemos insulinoterapia, não observando, em ambos, modificação da melhora que já tínhamos conseguido com a guanetidina.

5) Relação entre alucinação e delírio - Verificamos um fato que nos parece de máxima importância: a redução do delirio esteve sempre na dependência da eliminação das alucinações, quando existiam. Cessadas as alucinações, quase sempre de forma mais ou menos súbita, o delirio se reduzia, sempre gradativamente, até a extinção. Após a alucinação, o primeiro a ceder é o "humor delirante", desaparecendo, depois, o interêsse de delirar e a convicção delirante para, finalmente, ceder tôda produção delirante. Há um periodo que, aparentemente, estaciona essa redução - "estado latente de ajuste" — mas durante o qual o paciente aproveita para, mediante acontecimentos reais, racionalizar seu delírio e ajustar-se, progressivamente, à realidade. Mesmo nos casos em que foi possivel comprovar alucinaçōes, o processo de redução do delírio foi o mesmo. Dependendo da maior ou menor capacidade intelectual, pode estabelecer-se o "insight". Nos casos em que havia alucinaçōes, elas foram por nós valorizadas de forma que não deixassem margens à dúvida.

6) Ação da guanetidina sôbre a pele - Fato curioso que observámos durante o tratamento com a guanetidina: a melhora da sintomatologia sempre coincidiu com melhoria do aspecto da pele do rosto, melhoria que persistiu após a cura clinica e mesmo depois de interrompido o tratamento. Pareceu-nos que a pele tornava-se mais "sadia" e mais "limpa", como que rejuvenescida. Tôdas as vêzes em que houve agravamento da sintomatologia, mesmo nos periodos de superdosagem, havia, simultâneamente, piora do aspecto da pele, que se tornava mais gordurosa e mais "grossa", como que envelhecida.

Sabemos que êste "sinal" tem valor muito relativo. Trata-se de "sintoma de expressão" que, de acôrdo com K. Schneider, transforma-se em impressão do observador e sujeito, portanto, a todos os erros subjetivos possiveis. De qualquer maneira, assinalamos o fato para que outros possam observa-lo.

7) Ação da guanetidina sôbre a conação e o afeto - Todos os casos reagiram de forma surpreendente à guanetidina. Pode parecer paradoxal que exatamente os casos nos quais os distúrbios incidam mais acentuadamente na esfera da conação, responderam mais prontamente à medicação. Entretanto, só os pacientes que apresentavam acentuado comprometimento da vontade (catatônicos) permaneceram por menos tempo em cura clinica. Nossos dois catatônicos permaneceram clinicamente curados, no máximo, durante 70 dias após a interrupção da guanetidina.

Nos casos cuja participação afetiva nos sintomas era mais intensa, os pacientes demoraram mais a beneficiar-se com a guanetidina, mas a remissão foi mais 
espetacular, sendo êstes os casos que estão resistindo mais a um nôvo surto. Apenas um dos nossos esquizofrênicos paranóides apresentou recidiva, após ter permanecido por 8 meses em cura clínica. Nenhum outro paciente dêste grupo (paranóide, parafrênico e simples) apresentou recidiva até a data em que êste trabalho foi redigido.

\section{CAUSiSTICA}

Caso 1 - J. L. F., sexo masculino, com 25 anos de idade, branco, brasileiro, solteiro, lavrador, internado em 26-12-1962 (R.G. 84075) e examinado em 22-2-1963. Biótipo atlético. Personalidade pré-mórbida esquizóide. Tempo de evolução da enfermidade: 6 meses. Forma evolutiva indeterminável. E a primeira vez que apresenta distúrbios mentais. Inicio da enfermidade em meados de dezembro de 1562. Sintomatologia - Internado em crise de agitação, apresentou, alguns dias depois, sintomatologia catatônica. Após 6 eletrochoques ficou novamente agitado, intensamente desagregado e incoerente, mas lúcido. Submetemo-lo a 30 comas insulínicos, após o que o paciente apresentou-se calmo, lúcido, desagregado, incoerente, com maneirismos de mimica (careteia, esconde o rosto, ri inexpressivamente e sem motivo aparente) e sindrome de influência, caracterizada por influência magnéticas estranhas, fenômenos telepáticos, interceptação do pensamento e alucinaçōes cenestésicas. Diagnóstico: esquizofrenia paranóide.

Tratamento pela guanetidina e evolução - Iniciamos o tratamento em 19-6-63. No 17.9 dia verificamos o início da remissão e, aos 47 dias, o paciente se apresentava clinicamente curado, o que nos levou a interromper o tratamento. Sete dias após ocorreu recidiva, com agravamento progressivo. Reiniciamos a administração da guanetidina ao completar o 10.9 dia de interrupção e, 6 dias depois, o enfermo voltou a apresentar remissão, sendo considerado como clinicamente curado aos 97 dias. Só interrompemos a administração do medicamento aos 172 dias do reinicio do tratamento. Teve alta do hospital com licença experimental de 60 dias em 28-2-64. Foi revisto e continuava clinicamente curado em 27-4-64, em 27-7-64 e em 9-12-64. Resultado final - remissāo total.

Caso 2 - A. C., sexo masculino, com 18 anos de idade, branco, brasileiro, solteiro, sem profissão definida, internado em 28-11-62 (R.G. 84.728) e examinado em 5-1-63. Biótipo leptossômico. Personalidade pré-mórbida com caracteristicas de dependência infantil. Tempo de evolução da enfermidade: 9 meses. Forma evolutiva indeterminável. E a primeira vez que apresenta disturbios mentais. Início da enfermidade em novembro de 1962. Fizemos 5 eletrochoques, 30 comas insulinicos e impregnaçāo pela trifluorpromazina sem quelquer resultado. Sintomatologia Súbita e inexplicável modificação do comportamento. Escassa produção de sintomas. Lúcido, calmo, tímido, infantil. Olhar fixo. Mímica apagada. Autismo. Carência de iniciativa. Dificilima penetração psicológica. Fala em voz cochichada. Eco da palavra falada. Mussitação. Inexpressividade. Alucinações auditivas Não se considera doente. Indiferente ao meio e à situação. Diagnóstico: esquizofrenia simples.

Tratamento pela guanetidina e evolução - Iniciamos o tratamento em 22-8-63. No $10 .{ }^{\circ}$ dia verificamos o início da remissão e, no 19.9, o paciente apresentava-se clinicamente curado. Interrompemos a administração da guanetidina ao completar 50 dias de tratamento. Em 31-10-63 teve alta do hospital clinicamente curado, nāo retornando para contrôle. Resultado final - remissão total.

Caso 3 - H. S., sexo masculino, com 62 anos de idade, brasileiro, branco casado, internado em 21-6-63 (R.G. 86.561) e examinado em 12-9-63. Biótipo leptossónico. Personalidade pré-mórbida "normal". Tempo de evolução da enfermidade: 6 meses. Forma evolutiva indeterminável. E a primeira vez que apresenta distúrbios mentais. Sintomatologia - Lucidez de consciência. Contato e penetração psicológica dificil. Deprimido, chora fảcilmente. Introvertido. Carente de inicia- 
tiva. Tentativa de suicídio. Alucinações auditivas e visuais. Sentimento de doenৎa. Delírio persecutório. Sentimento de ameaça física. Diagnóstico: parafrenia.

Tratamento pela guanetidina e evoluçóo - Iniciamos o tratamento em 13-9-63. A sintomatologia comecou a remitir no $5.9^{\circ}$ dia e, no $46 .{ }^{\circ}$, o paciente estava clinicamente curado. Interrompemos o tratamento ao completar 59 dias e, 7 dias depois, o paciente começou a estabelecer "insight". No 38..$^{\circ}$ dia da interrupçāo do tratamento verificamos um leve surto que durou 4 dias e remetiu espontâneamente. Foi reexaminado e permanecia cllnicamente curado em 3-1-64, em 18-1-64, em 29-1-64, em 14-2-64, em 15-4-64, em 5-5-64, em 21-12-64 e em 24-3-65. Recebeu alta do hospital com licença experimental em 16-2-64. Resultado final - remissão total ccm "insight".

Caso 4 - R. F. B., sexo masculino, com 39 anos de idade, brasileiro, branco, sclteiro, escriturário, internado em 23-11-1960 (R.G. 79.480) e examinado em 13-12-1050. Biótipo leptossômico. Personalidade pré-mórbida acentuada tendência paranóide. Tempo de evoluç̃o da enfermidade: 10 anos. Forma evolutiva contínua. Inicio da enfermidade em 1953. Esteve internado 4 vêzes em diferentes sanatórios nos primeiros 5 anos de doença. Nas duas primeiras internaçōes foi submetido a eletrochoques e insulinoterapia, nas duas últimas à impregnação pela clorpromazina. Recebeu alta "muito pouco melhor" nas 4 vêzes, sem condições de retôrno ao trabalho. Internado no Hospital de Juqueri fizemos, durante dois anos mais ou menos, os seguintes tratamentos: impregnação pela trifluorpromazina e flufenazina, Sakel (30 comas) e Georgi (30 comas e 10 eletrochoques) sem que apresentasse qualquer melhora. Sintomatologia - Lucidez de consciência. Não se reconhece doente. Excitado. Agressivo. Impulsivo. Desagregado e incoerente. Introvertido. Percepção delirante. Idéias delirantes megalomaníacas e persecutórias rígidamente sistematizadas. Falsos reconhecimentos. Fenômenos telepáticos. Alucinações auditivas. Diagnóstico: esquizofrenia paranóide.

Tratamento pela guanetidina e evolução - Foi o primeiro caso que tratamos com a guanetidina. Iniciamos o tratamento em 29-4-1963. No 20.\% dia, após 10 anos de enfermidade, o paciente começou a responder favoràvelmente ao tratamento e, aos 72 dias, estava clinicamente curado. Nessa ocasião, numa tentativa para consolidar a cura, fizemos impregnação pela trifluorpromazina sem observar modificação no ritmo de melhora que o paciente vinha obtendo. No $100 .{ }^{\circ}$ dia iniciou-se o estabelecimento do "insight". AOs 135 dias interrompemos o tratamento e o paciente teve alta do hospital em 7-11-1963. Revisto 5 meses depois da alta, continuava clinicamente curado. No $8 .^{\circ}$ mês foi reinternado, a conselho nosso, pois comecava a apresentar sinais de recidiva. Submetido, novamente, à guanetidina (de 14-8-64 à 5-10-64) conseguimos apenas remissão parcial: desapareceram as alucinaçōes auditivas; abrandou o delírio (o doente só falava nêle quando solicitado e, assim mesmo, procurando desvalorizá-lo); melhorou a excitação e a irritabilidade. Submetido a impregnação por um derivado butirofenônico, acentuou-se a remissão obtida com a guanetidina. O paciente teve alta do hospital com licença experimental de 90 dias em 13-4-65. Reexaminado cada 30 dias, até esta data, verificamos a progressiva melhora até a remissão total com estabelecimento da "insight". Fato curioso: durante o tratamento com a guanetidina e coincidindo com a remissāo da sintomatologia, houve remissão de eczema sêco, localizado na região têmporo-parietal esquerda. Quando reinternado, apresentava agravamento do eczema que voltou a melhorar, simultâneamente, com a melhora da sintomatologia psiquica, após a administração da guanetidina. Resultado final - remissão total com "insight".

Caso 5 - J. F. P., sexo masculino, com 45 anos de idade, brasileiro, branco, casado, ferreiro-carpinteiro, internado em 4-6-1962 (R.G. 83.287) e examinado em 19-6-1963. Biótipo displásico. Personaliáade pré-mórbida caracterizada por deficit de iniciativa, pouca sociabilidade, ambições limitadas e afetividade "rigida". Tempo de evolução da enfermidade: 4 anos. Forma evolutiva em surtos. Início da enfermidade nos últimos dias de 1959. Apresentou 4 surtos anteriores. Nos dois pri- 
meiros houve remissāo da sintomatologia catatônica após eletrochoques, recebendo alta do hospital e retornando ao trabalho. No terceiro surto a sintomatologia remitiu após eletrochoques e um coquetel lítico (Amplictil, Fenergan e Gardenal) e, no 4.9 surto, houve remissão depois de duas séries distintas de 5 eletrochoques, Com o aparecimento do 5.9 surto, foi reinternado no Hospital de Juqueri em 24-5-63 e submetido à guanetidina. Sintomatologia - Contato e penetração psicológica precaríssimos. Lucidez de consciência. Agitação. Agressividade. Negativismo. Mutismo. Flexibilidade cérea. Mussitação, Insônia. Autismo. Diagnóstico: esquizofrenia catatônica.

Tratamento pela guanetidina e evolução - Inciamos o tratamento em 19-6-63. No 17.9 dia verificamos o início da remissão e, no 22.9 , estava clinicamente curado. Fizemos 5 eletrochoques a partir do 31.9 dia de tratamento, julgando-o em remissão parcial, sem que se modificasse a remissão obtida com a guanetidina. Após termos colhidos os informes, soubemos tratar-se de remissão total e interrompemos a administração do medicamento ao completar 55 dias de tratamento e concedemos alta cllnicamente curado. Setenta dias após a interrupção do tratamento apresentou o 6.9 surto, que remitiu totalmente depois de submeter o paciente ao tratamento com a guanetidina, sem que tivessemos feito, nesta oportunidade, eletrochoques. Des dias após a interrupção do tratamento apresentou ligeiro agravamento da sintomatologia no que diz respeito ao relacionamento com o meio, ao contato e ao humor. Submetido a um derivado butirofenónico, houve acentuada melhora da remissāo já obtida com a guanetidina. Teve alta do hospital com licença experimental de 90 dias, prorrogada por mais 180. Resultado final - remissāo total.

Caso 6 - A. M. C., sexo masculino, com 21 anos de idade, brasileiro, solteiro, sem profissão definida, internado em 1-11-62 (R.G. 84.475) e examinado em 1-2-63. Biótipo atlético. Personalidade pré-mórbida ignorada. Tempo de evolução da enfermidade: 20 meses. Forma evolutiva contínua. Inicio da enfermidade em 30-10-61, tendo sido submetido a impregnação pelo Tementil e 30 comas insulínicos sem resultado. Sintomatologia - Excitado e agressivo. Lucido. Mau contato. Dificil penetração psicológica. Alucinações auditivas. Idéias delirantes megalomaníacas e persecutórias. Auto-referência. Transmissão e interceptação do pensamento. Delírio de influência. Diagnóstico: esquizofrenia paranóide.

Tratamento pela guanetidina e evolução — Início da remissão no 21.9 dia de tratamento e, no 39.9 , a remissāo era bem mais acentuada, mas, infelizmente, não soubemos valorizá-la convenientemente e interrompemos o tratamento, o que ocasionou acentuado agravamento da sintomatologia 7 dias depois. Durante a remissão parcial apresentou melhoras da agressividade, do contato, da penetração psicológica, distanciando os agressores e melhorando do delírio. Não melhorou das alucinações, mas repercutem menos e no quarto-forte diminuiam (antes reclamava do "vozeirio" no Q.F.). Resultado final — remissão parcial (tratamento incimpleto).

Caso 7 - J. A., sexo masculino, com 28 anos de idade, brasileiro, branco, solteiro, internado em 4-7-62 (R.G. 83.484) e examinado em 25-3-63. Biótipo leptossômico. Personalidade pré-mórbida "criançola", com tendência hipomaníaca. Tempo de evolucão da enfermidade: 5 anos. Forma evolutiva em surtos. Inicio da enfermidade em 1958. Internado em sanatório particular, ignoramos os tratamentos efetuados, sabemos, porém, que não apresentou melhoras. No Hospital de Juquerí foi submetido a 30 comas insulínicos e impregnaçāo pela trifluorpromazina, apresentando remissão parcial da sintomatologia. Houve recidiva 4 meses depois com remissão discreta após 30 comas insulínicos. Nôvo agravamento em 20-8-63, tendo sido submetido à guanetidina. Sintomatologia - Lúcido. Mau contato. Humor de palhaço. Desinteressado. Sem noção de doença. Alucinações auditivas. Delírlo persecutório. Agitado. Logorrêico. Canta, gargalha, grita. Neologismo. Risos puerís. Impulsos agressivos. Aprobatividade. Diagnóstico: esquizofrenia hebefrênica.

Tratamento pela guanetidina e evolução - Inicio do tratamento em 20-8-63. A remissão começou no $11.9^{\circ}$ dia de tratamento e, no 47.9 , achava-se clinicamente 
curado. Interrompemos a administração do medicamento ao completar 80 dias de tratamento. Teve alta do hospital com licença experimental de 90 dias em 2-12-63. Foi revisto e renovamos a licença em 2-3-64 e em 1-6-64. Reinternado em 21-6-64 com recidiva, nāo reiniciamos o tratamento com a guanetidina por falta do medicamento. Resultado final - remissão total.

Caso 8 - F. F., sexo masculino, com 29 anos de idade, brasileiro, branco, solteiro, calceteiro, reinternado em 15-7-65 (R.G. 81.251) e examinado em 21-8-63. Biótipo pícnico. Personalidade pré-mórbida ignorada. Tempo de evolução da enfermidade: 2 anos. Forma evolutiva em surtos. Ignoramos os antecedentes. A enfermidade parece ter começado em 10-8-61, ocasião em que foi internado no Hispital de Juqueri. Submetido a $\mathbf{3 0}$ comas insulinicos, 8 eletrochoques e impregnação pela trifluorpromazina, recebeu alta do hospital em "remissão social" no dia 21-3-62. Reinternado um ano depois, fugiu duas vêzes, após ter feito tratamento incompleto de impregnação e três eletrochoques, dos 10 que lhe foram prescritos, sem que se pudesse avallar os resultados. Retornou ao hospital menos de um mês depois da última fuga. Sintomatologia - Lúcido. Só responde se estimulado. Admite estar doente, "mas não louco". Crê estar "encantado". Advinha pensamento e o futuro. Sabe tudo o que se passa no mundo. Autismo alternante. Foi à Palácio para casar com a fllha do Governador. Vontade influida. Alucinações auditivas e cenestésicas. Desinteressado da alta. Diagnóstico: esquizofrenia paranóide.

Tratamento pela guanetidina e evolução - No 10.9 dia de tratamento verificamos o inicio da remissão, que se mostrou muito mais acentuada no $32 .{ }^{\circ}$ dia, mas o enfermo fugiu uma semana depois e não retornou até esta data. A remissão parcial obtida durante o tratamento consistiu no seguinte: melhorou do autismo; interessou-se pela alta; quer tratar da vida e arranjar emprêgo; desinteressou-se pela filha do Governador; manifesta dúvidas quanto ao "encanto", admitindo estar apaixonado; justifica suas fugas constantes dizendo que as vozes (da mulher amada) o aborrecem, por isso foge, mas retorna porque se sente "prêso a ela". Relativo "insight" quanto ao "encanto". Continuavam as alucinações e certa dependência. Resultado final - remissão parcial (tratamento incompleto).

Caso 9 - J. H. F., sexo masculino, com 45 anos de idade, branco, brasileiro, casado, lavrador, internado em 10-10-62 (R.G. 84.256) e examinado em 4-9-63. Biótipo displásico. Personalidade pré-mórbida ignorada. Tempo de evolução da enfermidades 28 meses. Forma evolutiva contínua. O início da enfermidade data de abril de 1961. Internado no Hospital de Juqueri, foi submetido a 30 comas insulínicos sem resultado. Sintomatologia - Lúcido. Contato regular. Penetração psicológica difícil. Excitado. Logorreico. Colérico. Não se reconhece doente. Atitude autoritária e de superioridade. Alucinaçōes auditivas. Sente-se vigiado. Delírio persecutório, megalomaníaco e de prejuizo. Desagregado. Incoerente. Déficit intelectual. Diagnóstico: esquizofrenia paranólde em oligofrênico.

Tratamento pela guanetidina e evolução - Inicio do tratamento em 26-8-63. No 5.9 día iniciou-se a remissão $e_{*}$ no 29.9, verificamos a remissão máxima, que consistiu no seguinte: melhorou o humor, o "tom afetivo", a agressividade e o "insight"; a atitude passou a ser de humanidade e respelto; desapareceram as alucinações e as idélas persecutórias e de prejuizo. Embora conservasse algumas idéias de grandeza, elas eram menos exuberantes e o enfermo não se referia a elas espontãneamente. No 35.9 dia aumentamos a dose díaria para $100 \mathrm{mg}$ e, 15 dias depois, o paciente apresentava recrudescimento da sintomatologia, que persistiu até 11 dias depois de termos reduzido a dose pela metade, após o que melhorou progressivamente até alcançar a remissão anterior. No 86.9 dia de tratamento, como a remissāo permanecesse estável, associamos 30 comas insulínicos que não influiram na remissāo que já tinhamos obtido. O tempo de duração do tratamento foi de 6 meses. Reexaminado em 10-3-64, em 20-3-64, em 8-4-64, em 15-4-64 e em 1-7-64, o paciente permanecia em remissão parcial. Apresentou, apenas durante uma semana (de 8 a 15-4-64), crise de agitação psicomotora que não interferiu nos "restos delírantes" e nem provocou alucinações. Medicado com um derivado 
butirofênonico, o paciente retornou à calma após 7 dias. Teve alta do hospital com licença experimental em 1-7-64, nāo retornando para renová-la. Resultado final - remissāo parcial.

Caso 10 - W. C. X., sexo masculino, com 35 ano de idade, brasileiro, branco, solteiro, lavrador, internado em 18-10-62 (R.G. 84.357) e examinado em 19-1-63. Biótipo leptossômico. Personalidade pré-mórbida ignorada. Tempo de evolução dá enfermidade: provảvelmente menos de um ano. Forma evolutiva indeterminável. E a primeira vez que apresenta distúrbios mentais. Durante 7 anos viveu na casa de parentes que não sabem dar informes. De 1954 a 1962 esteve "desaparecido". Em outubro de 1962 retornou à residência com sintômas de doença mental. Internado no Hospital de Juqueri, foi submetido à 5 eletrochoques e 30 comas insulínicos sem resultado. Sintomatologia - Lúcido. Contato e penetração psicológica precarissimos. Desorientado. Desinteressado. Flexibilidade cérea. Aprobatividade. Autismo. Imóvel. Mussitação. Fácies de "zangado". Diagnóstico: esquizofrenia catatônica.

Tratamento pela guanetidina e evolução - Início da remissão no 16.9 dia de tratamento e, no 23.9 dia, verificamos a remissão máxima, que consistiu no seguinte: melhorou o humor, a iniciativa, o contato e o relacionamento com o meio; sorria e respondia mais fàcllmente às perguntas. Fizemos 5 eletrochoques, a partir do 30.9 dia de tratamento, sem que se modificasse a remissāo já obtida. Ao completar 55 dias de tratamento, interrompemos a administraçāo do medicamento. Foi reexaminado e continuava em remissão parcial, no $5 .{ }^{\circ}$, no $12 .^{\circ}$, no $25 .{ }^{\circ}$, no $33 . .^{\circ}$ e no 58.9 dia após a interrupção. Apresentou recidiva três meses e meio depois da interrupçāo e nāo pudemos reiniciar o tratamento por falta do produto. Resultado final — remissão parcial.

Caso 11 - P. F. N., sexo masculino, com 27 anos de idade, brasileiro, branco, solteiro, internado em 26-3-63 (R.G. 85.807) e examinado em 28-3-63. Biótipo leptossômico. Personalidade pré-mórbida ignorada. Tempo de evolução da enfermidade: provảvelmente menos de um ano. Forma evolutiva indeterminável. E primeira vez que apresenta distúrbios mentais. Ignoramos sua vida pregressa e a história da doença atual. Provável inicio da enfermidade em março de 1963, quando foi internado no Hospital de Juqueri e medicado, durante 55 dias, com um derivado butirofenônico, na dose de $3 \mathrm{mg}$ diários, sem resultado. Sintomatologia Lúcido. Excitado. Logorrēico. Difícil penetração psicológica. Delírio de enormidade (lembra P.G.P.). Incoerência. Puerilidade. Influência sôbre a vontade. Prolixidade. Falsos reconhecimentos. Delírio megalomaniaco, persecutório e de prejuizo, intenso e rico. Alucinações auditivas. Deficit intelectual. Diagnóstico: esquizofrenia paranóide em oligofrênico.

Tratamento pela guanetidina e evolução - A remissâo teve inicio no 8.9 dia de tratamento e alcançou grau máximo no 36.9. A remissão consistiu no seguinte: melhorou muito da excitação; melhor contato e mais fácil penetração psicológica; cessaram as alucinações; abrandaram as idéias delirantes; perdeu o interêsse de falar do delírio e só o faz quando solicitado, mas sem a vivacidade e a convicção anterior ao tratamento. No $110 . .^{\circ}$ dia de tratamento, apresentando remissão parcial estável, associamos tratamento de impregnação pela trifluorpromazina, mas nāo verificámos modificação no resultado já obtido. Interrompemos a administração do medicamento ao completar 141 dias de tratamento e reexaminamos o paciente no $12 . .^{\circ}$ e no $40 .^{\circ}$ dias após a interrupção. Em abril de 1964 o enfermo fol removido para a Divisão Colônias em remissão parcial. Resultado final — remissāo parcial.

\section{COMENTARIOS}

Tomando por base os dados aqui expostos, estabelecemos uma teoria que representa nossa modesta contribuição no sentido de permitir o esclare- 
cimento étiopatogênico da esquizofrenia. Trata-se de teoria simples, mas realista, que poderá ser comprovada experimentalmente. Acreditamos que ela contribuirá para o início de pesquisas realmente objetivas sôbre as "doenças mentais" em geral e a esquizofrenia em particular. Bem sabemos que, para uma avaliação exclusivamente terapêutica, o número de casos tratados é pequeno e, apesar dos surpreendentes resultados obtidos, merecerá confirmaçāo ulterior no que diz respeito às curas clínicas. Mas, não estamos interessados em destacar nossa teoria, nem o valor terapêutico de nossa pesquisa, embora êle exista.

O que nos interessa é ressaltar a conclusão mais importante que se tira dos resultados dessa pesquisa e que autoriza uma nova abordagem, senão o reexame total dos critérios adotados até hoje, nas pesquisas à procura da etiopatogênia da esquizofrenia, e que se acha demonstrado por um fato indiscutível: um medicamento cujo mecanismo de ação é, muito provàvelmente, de nenhuma ou de escassa ação central, mas de indiscutivel ação peri. férica interferiu, com impressionante regularidade e uniformidade, na patogenia da esquizofrenia como nenhum outro medicamento utilizado até hoje.

Todos os casos $(100 \%)$ responderam favoràvelmente a ação da quanetidina. Desejamos salientar estarem incluídos em nosso material os 5 tipos clássicos de esquizofrenia; que o tempo de evolução da enfermidade, nos diferentes casos, é dos mais variados (desde 6 mêses até 10 anos); que se encontram no nosso material todos os biótipos considerados básicos; que estão incluídos casos nos quais os enfermos não tinham ainda sido submetidos a nenhum dos tratamentos clássicos e outros nos quais um ou mais dêssees tratamentos já tinham sido tentados e que temos casos tanto de evolução contínua quanto de evolução em surtos. Quanto aos sintomas psicopatológicos, comprovámos os seguintes efeitos da guanetidina: as alucinações foram eliminadas nos 5 casos de remissão total que as apresentavam e, nos 4 casos de remissão parcial que tinham alucinações, foram eliminadas em dois e abrandadas nos outros dois. O delírio foi eliminado em 4 dos casos em que houve remissão total e. nos casos em que houve remissão parcial, abrandou-se em três, só influindo pouco em um. O mau contrato foi eliminado em 6 dos pacientes que remitiram totalmente e melhorou em 4, dos 5 pacientes, que remitiram parcialmente; o outro não prosseguiu no tratamento. Quanto à conação, a guanetidina sempre teve efeito na agitacão, na agressividade e no negativismo. No que diz respeito aos distúrbios do $\mathrm{Eu}$, houve casos resolvidos de todo e casos resolvidos parcialmente.

A guanetidina não respeitou nenhum dêsses fatôres e foi desvalorizando um a um dêsses critérios quase seculares. Nem mesmo o tão decantado critério pragmático ou "euristico" - no dizer de Berge e Ghrule — de evolução "contínua" e em "surtos", resistiram, nos casos aqui registrados, à ação da guanetidina. Diante disso, é lícito perguntar: qual é a importância dêsses fatôres nas pesquisas que visam estabelecer a etiopatogenia da esquizofrenia? Qual é o interêsse, por exemplo, de se estabelecer com exatidão o tempo de evolução duvidoso de dois casos nossos; do tipo de esquizofrenia ou sua forma evolutiva?

Resumindo, na nossa casuística não houve sintoma psicopatológico particularmente resistente à medicação. Repetiu-se o fato: os sinais psicopa- 
tológicos que decidem o diagnóstico de esquizofrenia, chamados sinais de primeira categoria, não são os mais resistentes à cura; indicam o diagnóstico, mas não o prognóstico face à guanetidina. Apenas um único fator, realmente útil, pode ser destacado: é a necessidade de que o "processo esteja em marcha". Em todos os nossos casos o processo estava em atividade.

Os resultados significativos que obtivemos e as conclusões que daí tiramos é que nos levam a sugerir que as pesquisas, para elucidar a etiopatogenia da esquizofrenia, devam ser reformuladas sôbre mais um modo de abordagem, e êste inteiramente nôvo, e em que o mecanismo de ação da guanetidina pode ajudar a entender o enigma que é a esquizofrenia. Parece-nos que, mesmo levando em conta o sistema nervoso central, o sistema nervoso periférico desempenha um papel fundamental na patogenia dos sintomas e, quiçá, na etiologia da esquizofrenia. $\dot{E}$, pelo menos, o que o resultado de nossa pesquisa diz ser possivel. A partir dêsses elementos é que uma TEORIA PSICOSSOMÁTICA DA ESQUIUOFRENIA parece plausivel.

Não desejando invadir seára alheia, evitaremos cair no atraente mas inútil, terreno especulativo e aguardaremos que os farmacologistas e fisiologistas nos forneçam dados mais precisos a respeito do mecanismo de ação da guanetidina e que novos estudos confirmem nossos resultados para, depois, darmos publicidade à nossa teoria.

\section{RESUMO}

Foram tratados 11 casos de esquizofrenia com a guanetidina, substância considerada, do ponto de vista farmacodinâmico, como simpaticoplégica. $\mathrm{Na}$ opinião do autor, os surpreendentes e significativos resultados obtidos autorizam uma nova abordagem nas pesquisas à procura da etiopatogenia da esquizofrenia e, a partir dos elementos colhidos, considera plausivel uma "teoria psicossomática da esquizofrenia". Recusa-se, entretanto, a cair no atraente, mas inútil, terreno especulativo. Prefere aguardar que os farmacologistas e fisiologistas forneçam dados pais precisos sôbre o mecanismo de ação da guanetidina e que novos estudos confirmem seus resultados para, depois, dar publicidade à sua teoria.

\section{SUMMARY}

\section{A new approach to the treatment of schizophrenia}

Eleven cases of schizophrenia were treated with guanethidine, substance considered as a sympathicoplegic drug. In the author's opinion, the remarkable and significative results achieved justify a new approach in the investigation of the schizophrenia etiopathogenesis. As from the achieved elements, he considers plausible a "schizopherenia psychosomatic theory". However, he refuses entering the infructuous although attractive speculation field. He prefers to wait until the pharmacologists and physiologists can furnish more precise data regarding the guanetidine activity mechanism 
and new trials can corroborate the results achieved by him, and after that he will divulge his theory.

\section{REFERENCIAS}

1. BREST, A. N. \& MOYER, J. H. - Newer approaches to antihypertensive therapy. J. A. M. A. 172: 1041 (marco, 5), 1960. 2. BURN, J. H. \& RAND, M. J. Action of sympathomimetic amines in animals treated with Reserpine. J. Physiol. 144:314, 1958. 3. JASPERS, K. - Pslcopatologia General. Tradução castelhana da 5.^ ed. alemã, 9.* ediçăo, Editorial Beta, Buenos Aires, 1955. 4. MAXWELL, R. A.; MULL, R. P. \& PLUMMER, A. J. - 2-(octahydro-l-azocinyl)-ethyl-guanedine sulfate (CIBA 5864-Su); a new synthetic antihypertensive agent. Experientia. 15:267, 1959. 5. MAXWELL, R. A.; PLUMMER, A. J.; SCHNEIDER, F.; POVALSKI, H. \& DANIEL, A. I. - Pharmacology of 2-(octahydro-l-azocinil)-ethyl-guanedine sulfate (Su 5864). J. Pharmacology. exp. Ther. 128:22-29, 1960. 6. PIRES, N. - Comunicação pessoal. 7. PIRES, N. - O psiquíco em medicina. Bol. Centro de Estudos "Franco da Rocha", ano 6, n.9 3/4 (novembro-dezembro), 1962. 8. SCHNEIDER, K. - Problemas de Patopsicologia y de Psiquiatria Clínica. Tradução casteIhana, 1.a edição, Ediclones Morata, Madrid, 1947.

$$
\text { Hospital de Juquer - Franco da Rocha - Estado de São Pauto - Brasil. }
$$

